\title{
Comida en el arte contemporáneo. Restauración, conservación y reactivación del Eat Art
}

\author{
Lorenzo Hortal Valverde
}

Resumen: El empleo de comida en arte contemporáneo introduce en la obra un material altamente sensible a la biodegradación que imposibilita su pervivencia para el futuro, así como una fuerte intención interactiva que invita al público a participar comiéndose literalmente las piezas.

Desde el punto de vista de la restauración y conservación, el presente artículo intenta dar respuestas a los numerosos interrogantes que surgen en el profesional que se enfrenta a una obra de Eat Art. En él se realizará un repaso histórico desde la introducción del alimento en la obra hasta la actualidad. Tras sentar las bases de este movimiento, se expondrán las principales problemáticas que presenta. Se diseñarán estrategias de conservación para las mismas, prestando especial atención a la clasificación y diferenciación de las distintas tipologías existentes. Con ello se establecerán tratamientos y actuaciones adecuadas, dependientemente de la intención del artista y el respeto al significado de su obra.

Palabras clave: Arte contemporáneo, Eat Art, Comida, Performance, Arte efímero, Biodegradación.

\section{Comida em arte contemporânea. Restauro, conservação e re-activação da Eat Art}

Resumo: A utilização de comida em arte contemporânea introduz na obra um matéria altamente sensível à biodegradação que impossibilita a sua sobrevivência para o futuro, assim como encerra uma forte intenção interactiva que convida o público a participar, literalmente comendo as peças.

Desde o ponto de vista da conservação e restauro, o presente artigo tenta dar respostas às numerosas questões que surgem ao profissional que se confronta com obras de Eat Art. Vai ser feita uma retrospectiva histórica desde a introdução de comida até à actualidade. Após estabelecer as bases deste movimento serão expostas as principais problemáticas que apresenta. Para estas serão propostas estratégias de conservação, prestando especial atenção à classificação e diferenciação entre as diversas tipologias existentes. Serão estabelecidos tratamentos e actuações adequadas dependendo da intenção do artista e do respeito pelo significado da sua obra.

Palavras-chave: Arte contemporânea, Eat Art, Comida, Performance, Arte efémera, Biodegradação.

\section{Food in Contemporary Art: restoration, conservation and reactivation of the Eat Art}

Abstract: The use of food in contemporary art introduces a highly sensitive material to biodegradation, greatly complicating the future survival of the particular artwork. On the other hand, it represents a strong intention of performance, inviting the public to take part, literally eating up the pieces.

From the point of view of restoration and conservation, the given article tries to provide answers to the numerous questions arising in the professional who deals with works of Eat Art. A historical review will describe the development since food was first introduced in art. After laying the foundation of this movement, the principal challenges for restoration and conservation will be discussed. While paying special attention to the existing classifications and different typologies, strategies of conservation will be outlined in order to determine and conclude treatments and appropriate actions depending on the intention of the artist and respecting the meaning of the work of art.

Keywords: Contemporary Art, Eat Art, Food, Performance, Ephemeral art, Biodegradation. 


\section{Introducción}

[...] Todas las formas del hambre que caracterizan el amor nos guiaron en la creación de esta obra. Mediante nuestras manos, está aquí una expresión artística tan intensa como para exigir no sólo los ojos y relativa admiración, no sólo el tacto y relativas caricias, más los dientes, la lengua, el estómago, los intestinos igualmente enamorados [...].

Con estas palabras nos introduce Marinetti en su obra «La Cocina Futurista: Una comida que evitó un suicidio». La cita forma parte de una breve historia en la que un grupo de artistas se reúnen para encontrar la manera de impedir la muerte de un compañero por la pérdida de su amada. Para ello $y$, empleando distintos alimentos, elaboran un muestrario de mujeres comestibles para deleite de su amigo, de tal manera que tras devorar los cuerpos, la satisfacción de Giulio Onesti, el posible suicida, es tal, que su vida queda a salvo de la muerte.

Inevitablemente, las conexiones de este relato con algunos artistas contemporáneos son evidentes. La creación de la obra, en muchas ocasiones, pretende alcanzar un fin determinado y, por tanto, tener una vida finita. Marinetti y sus compañeros llevan a cabo la creación de unas esculturas comestibles con la esperanza de saciar la angustia de su amigo. Podemos reparar en distintas creaciones artísticas contemporáneas similares a las del relato: en ellas podremos encontrar un trasfondo canibalista, sexual o simplemente provocador. Ejemplos como los de Leandro Erlich y su Chocolate Couch, Messestand de Sonja Alhäuser o en mayor medida las PerforMANcenas de César Martínez [figura1] nos presentan piezas que interactúan con el espectador, que le obligan a que participe para entenderlas y que no están hechas simplemente para ser contempladas sino para ser comidas.

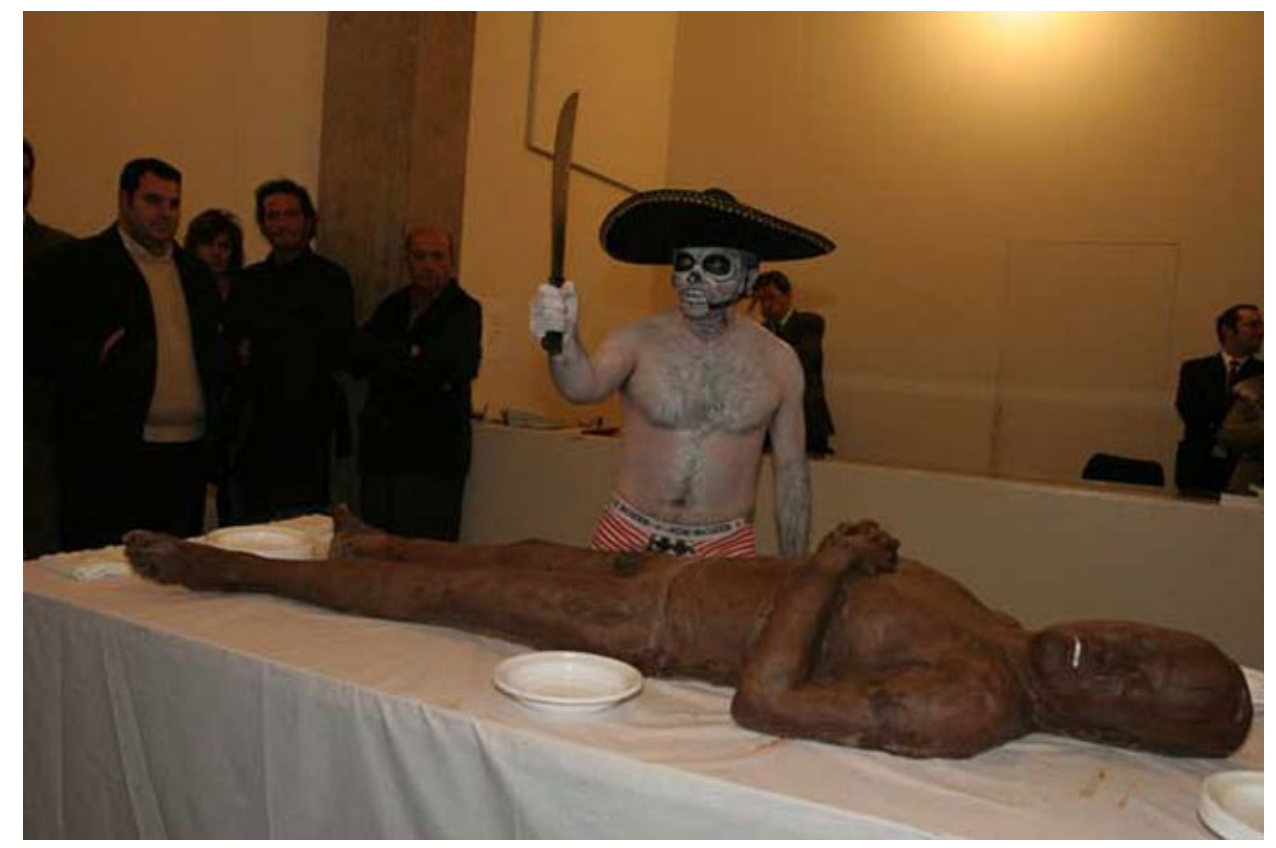

Figura 1. Neuroeconomía antropófoga, César Matinez. Centro Cultural Conde Duque. 11 de noviembre de 2004. Acto inaugural de la muestra "El imperdurable mente presente". OSofía Menéndez. 
Ahora bien, como restauradores-conservadores y, tras leer el relato de Marinetti, es imposible no reparar en el destino de las esculturas. Por un lado, la vida del compañero está a salvo, pero ¿y la de las obras? Éstas han muerto, han desaparecido y no podrán volver a ser vistas, ni comidas, por nadie. De las piezas solo quedan descripciones realizadas por el resto de compañeros, mera documentación, pero sin rastro de materia. ¿Cabe sentir lástima por su pérdida? Nuestra tarea en este momento será imaginar cuál debió ser su forma y apariencia, pero presenciarla físicamente será imposible. Esto nos lleva a una alternativa: la reactivación la obra.

Podría parecer un disparate cambiar de tiempo, de espacio y de protagonista, sin Giulio Onesti la obra nunca hubiese sido creada. Pero cabría plantearse si reactivándola se desvirtuaría su sentido, o en su lugar se recuperaría en una nueva dimensión, funcionando a modo de versión, dándole la oportunidad de volver a cumplir su función y de nuevo «evitar un suicidio».

\section{Problema de investigación}

Cabe plantearse la cuestión teórica del arte con comida de una manera sencilla y directa ¿Existe el arte con comida? La respuesta a esta pregunta puede tener un carácter evidente e incluso espontáneo, en cualquier caso la solución sería sí. Ahora bien, este estudio pretende indagar en una respuesta de mayor complejidad. Aún sabiendo que su contestación seguiría siendo sí, se pretenden clarificar los limites en los que una comida perfectamente cocinada y estéticamente presentada no puede formar parte de la disciplina arte, o por lo menos, no de la que aquí se intenta desmenuzar e investigar.

El Eat Art no tiene su origen en la gastronomía, su fin último no es alimenticio, sino artístico. Es necesario establecer las diferencias y tener claro que Antoni Miralda trabaja como un artista y Ferrán Adriá no. Mientras que Miralda formula con sus ideas piezas artísticas que se degustan no solo con el gusto, valga la redundancia, sino también con el intelecto, Adriá conforma alimentos dirigidos a la nutrición y satisfacción culinaria. Cierto es que las creaciones de Ferrán Adriá -no artísticas- también se consumen con la vista, y es posiblemente este punto el que más pueda confundir al espectador o comensal. Pero nunca debe confundirse, y siempre debe estar patente, el fin que motivó la creación de un plato del chef del momento o la producción de una obra de arte.

Al recopilar información sobre la introducción de la comida en el panorama artístico actual es fácil tropezarse con algo de caos respecto a los límites que conforman el Eat Art. Del mismo modo que no es igual hablar de alimentación que de gastronomía, no es lo mismo hablar de una obra de arte realizada con comida, que de una comida realizada de forma artística. En el presente texto se intentan distinguir los tipos de obras Eat Art para diferenciar claramente las obras de las no-obras y facilitar la tarea del restaurador conservador. El problema que intenta resolver esta investigación obliga a estudiar la comida y los distintos alimentos u objetos de cocina, y cómo estos guardan en sí, una fuerte significación que no está libre de connotaciones. Y son estas referencias intrínsecas lo que conformará un sinfín de posibilidades para los artistas. Los alimentos que forman parte de las obras no son simples pedazos de comida, frutas, carnes o trozos de bollería industrial. Tras ellas se esconden discursos trabajados previamente, que intentan comunicar algo, poseen un trasfondo o son el medio por el cual una obra puede darse por concluida. 


\section{Conservación y Restauración de Obras de Eat Art: Situación actual}

Pueden encontrarse diversidad de publicaciones en los que de forma sucinta se desarrolla la cuestión del arte con comida o Eat Art. En muchos casos se trata de ejemplos aislados que no conforman un documento potente que desarrolle en profundidad el tema. Ha sido en los últimos años cuando se han elaborado diferentes exposiciones con este tema como eje motor: catálogos como el de la exposición Eating the Universe celebrada en el museo Kunsthalle de Düseseldorf, Alemania, Comer o no Comer levada a cabo por el Centro de Arte de Salamanca (SA- LA), Eat Art: Joseph Beuys, Dieter Roth, Sonja Alhäuser de 2001 en Harvard, Eat Art (Come Arte) del Kunstmuseum de Stuttgart en 2010 o El arte del comer de la obra social Caixa Catalunya en La Pedrera de Barcelona, son exposiciones que muestran la atracción de muchos artistas por el tema de los alimentos como enlace fundamental del arte y la vida, y su gran relevancia en cuestiones tales como lo bélico, la abundancia o el hambre en el mundo. La primera exposición citada, Eating the Universe, examina los orígenes del Eat Art desde su creación por Daniel Spoerri, como temática artística, acompañada de la participación de diversos artistas que trabajan con su mismo concepto tales como Joseph Beuys, Sonja Alhäuser, Arman, Lili Fischer o Gordon Matta-Clark entre otros, unificándose de esta manera obras que inciden en un tema común.

Por otro lado, es interesante destacar la exposición Comer o no Comer, de la que como resultado fundamental, además de una interesantísima muestra compuesta por más de doscientas obras, surgió un compendio de textos, realizados por numerosos especialistas, que son posiblemente, la más completa revisión hasta la fecha, de las relaciones del arte y los alimentos en el siglo XX. Se han celebrado a su vez exposiciones que estudian el trabajo individual de determinados artistas, centrando la temática en el empleo de la comida para el discurso artístico, como en los casos de Sonja Alhäuser o Antoni Miralda.

Todos los textos de los catálogos citados anteriormente están enfocados hacia la explicación histórica e ideológica de muestras y exposiciones. La mayoría reparan en la identificación de obras y la interrelación entre unas y otras. En el catálogo de la muestra Comer o no Comer, a pesar de estar compuesto por más de quinientas páginas, no hay referencias a cuestiones de procedimientos ni materiales empleados, algo que para un especialista en la cuestión técnica, se echa verdaderamente en falta. No es sencillo encontrar estudios que reparen en las particularidades o problemáticas específicas de este tipo de piezas. Existen algunas referencias como la que Pilar Bustinduy hizo en la VI Jornada anual de Conservación de Arte Contemporáneo celebrada por el GEIIC y el MNCARS durante el año 2009, así como el congreso de conservación de escultura contemporánea que se realizó en la Tate Modern de Londres en 1995 titulado From Marble to Chocolate. En él se analizaron diferentes materiales empleados en la creación escultórica desde ejemplos realizados en piedra, madera y metales hasta algunos trabajos de arte en chocolate, analizados por Glenn Wharton, Sharon D. Blank y J. Claire Dean, en los que sí se consideran cuestiones como el deterioro del cacao, su composición química y técnicas de conservación en obras de William Mobley, Dieter Roth y Beuys, aunque solamente referidos a un único material, el chocolate.

No existen estudios que indaguen en los tratamientos a emplear en el arte con comida, tampoco una relación de obras desde el punto de vista material o físico. Cada obra es estudiada individualmente cuando la misma debe ser transportada, expuesta o tratada por un problema concreto. Es loable pero quizá insuficiente este trato individualizado y no en conjunto. Es frecuente que al centrarnos en la restauración y conservación del arte contemporáneo el hecho de establecer pautas generales o métodos únicos para actuar sobre las obras resulte complicado. Pero al hablar 
de piezas específicas dentro de una misma tipología, puede que dicha tarea sea efectiva y beneficie al Eat Art, en este caso, como conjunto. Se trata de obras con numerosas características en común que a su vez poseen diferencias muy notorias. Podemos estipular mediante su estudio pormenorizado ciertas medidas que de forma concisa ayuden a esclarecer el papel de la comida en el arte.

\section{Objetivos}

El hecho de que la comida sea el medio por el cual la obra cobra forma física, no quiere indicar en todos los casos que la obra deba ser ingerida o deba degradarse hasta la putrefacción. En muchas ocasiones la materia o comida debe permanecer inquebrantable, vigorosa al paso del tiempo. Con estas nociones de partida, el objetivo principal del estudio se centra en revisar la obra contemporánea realizada con comida, exponiendo la problemática específica de esta tipología y proponiendo actuaciones y tratamientos determinados. Creando con ello un documento interesante y útil desde el punto de vista de la restauración y conservación.

El discurso y eje vertebrador del estudio se basa en analizar la presencia de comida en la obra, no sólo en los casos en que dicha comida se muestra incluida en una performance u obra participativa. La investigación indaga en las cuestiones específicas de tres tipos de obras: ya sean con intención de durabilidad, de arte efímero o de piezas interactivas. Se repasa su historia así como el momento de su incorporación en el panorama artístico. A su vez se muestra, a lo largo del análisis, cómo estas obras deben ser entendidas y cuál debe ser la actitud del restauradorconservador ante unas determinadas características. Con esa información se han diseñado diferentes estrategias, formuladas para abordar cada una de las diferentes obras examinadas. El resultado se verá recogido en una tabla resumen, donde se mostrarán, de forma clara, las diversas opciones y soluciones aplicables. Contando siempre con la intención artística que la propia pieza presente.

\section{Metodología}

La investigación se dividió en cuatro partes fundamentales, que aunque separadas y diferenciadas, poseen una estructura fundamental que unifica el estudio, dándole una forma única y continuada. La metodología empleada partía de un plano general, abordando la comida en el arte de forma global y, poco a poco focalizando la atención en la creación contemporánea. Se analizó la problemática que estas piezas presentan y por último se aportaron soluciones y estrategias de conservación. A continuación se muestran, de forma reducida, los distintos capítulos de la investigación y sus correspondientes conclusiones:

\section{Resultados del trabajo:}

\section{Parte I. Relación entre arte y comida: revisión histórica}

La comida ha constituido una fuente de inspiración para los artistas, quienes según la época la han interpretado desde perspectivas muy distintas, dando como resultado obras categóricamente opuestas. Todos los atractivos que los alimentos tuvieron para los antiguos creadores siguen vigentes en las vanguardias y llega hasta el arte más actual de la mano de artistas que otorgan a estos materiales dimensiones nuevas y dispares que alientan nuevos relatos. 
Desde la pintura meramente ilustrativa o documental que nos muestra maneras de cocinar, platos típicos y banquetes referentes de épocas como la egipcia o la romana se ha realizado un viaje por la representación del alimento en las distintas religiones. La comida cobra sentido específico, convirtiéndose en símbolo, aunque siempre de manera anexa o complementaria en la obra y su composición [figura2]. Ya en los siglos XVI y XVII la llegada del bodegón haría que ésta saltara a un primer plano y se convirtiera en la protagonista de la escena. Pero dependiendo de la época de la obra, la comida se ha introducido con diversas intenciones, ya fuera como indicativo de una posición social en Vermeer o Van Gogh, como elemento caricaturesco de sátira o ironía en los geniales retratos de Arcimboldo o a modo de única protagonista de la composición ya en bodegones llenos de detalle como los de Luis Meléndez o Paul de Vos. Dicha tipología será rescatada constantemente por los artistas para abrir nuevos discursos, no deteniéndose sólo en el apartado estético, pudiendo además hacer referencias a temáticas religiosas, antropológicas, filosóficas o críticas para con la política del momento. Cada creador imprime en el bodegón su mirada única. Mientras que Chardin congelaba el instante en sus nítidas captaciones del momento, Cézanne, precursor de las formas abstractas, concedía un especial protagonismo a los elementos. Todo objeto sobre su mesa -jarra, taza o manzana- era tan significativo como cualquier figura dibujada en un «cuento» ilustrado (Charlesp 2011:42). Picasso presentará otra evolución en los objetos y alimentos de estas naturalezas muertas, en los diversos bodegones que realizó entre 1906 y 1908, mostrando la elocuencia vertiginosa de un nuevo lenguaje (Charlesp 2011:50). Gauguin, Matisse, Salvador Dalí, Juan Gris o Luis Fernández se servirán también de la potencia expresiva de la comida y sus elementos para plasmar sus imaginarios en el soporte artístico.

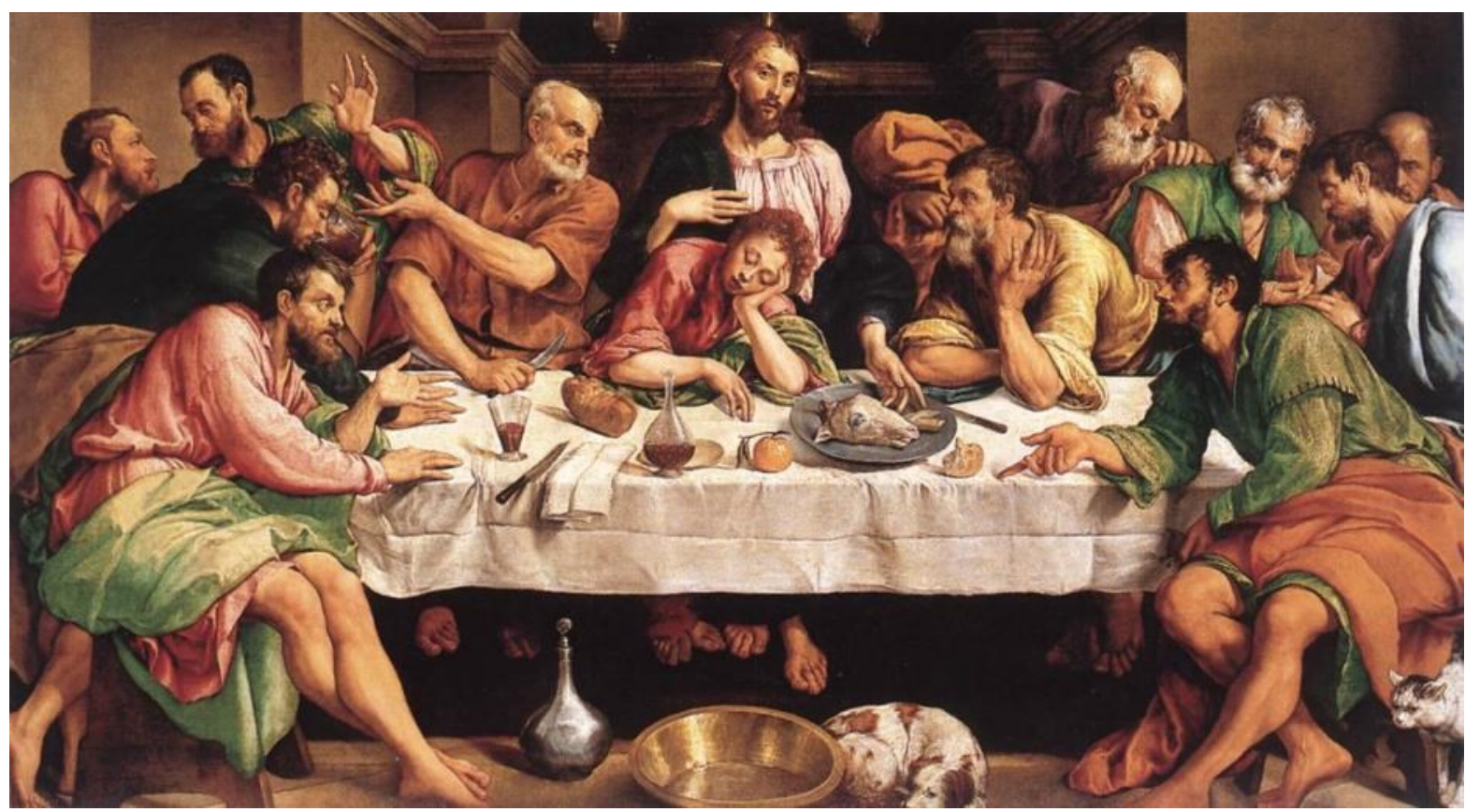

Figura 2. La última cena, Jacobo Bassano. c. 1546, Galleria Borghese, Rome.

Tras las creaciones de estos artistas modernos que aún están sujetas a una tradición de marcada inmovilidad, los artistas contemporáneos suponen un giro completo a la temática. El bodegón da paso a la representación de la comida como vehículo idóneo para los temas más dispares, enseñando al observador nuevas formas de mirar y de entender los objetos de cocina y los 
alimentos seleccionados. Josef Sudek, Mona Hatoum, Miralda, J. Sterbak o Macerl Broodthaers son claros ejemplos de ello. Con sus creaciones todo cobra una nueva dimensión, nuevos factores entran ahora a formar parte de la obra: el tiempo, la luz, el olor, el sabor o el propio espectador son parte de sus discursos artísticos.

\section{Parte II. Presencia de comida en arte contemporáneo}

La imposibilidad de lo real en la obra de arte dejó de ser una utopía, y con ella diferentes movimientos artísticos introdujeron objetos y enseres de lo cotidiano en el plano de la creación. El conceptualismo, líneas artísticas como el dadaísmo, Fluxus y muchas otras, hicieron posible la presencia real de la materia del día a día. Es en este punto cuando la comida, de la mano de Daniel Spoerri, se eleva como parte íntegra de la pieza y se presenta directa, sin engaños ni falsedades. Mientras que Willem Heda pintor holandés del siglo XVII ilustra en sus minuciosos óleos mesas ya usadas, repletas de restos de comida, trozos de pan y mondas de fruta, cubiertos y vajillas sucias acompañadas de bebidas medio vacías, Spoerri, en un discurso muy parecido, muestra una obra prácticamente idéntica, con la salvedad de que los platos son verdaderos platos, así como vasos, colillas y jarras, pan, carnes y frutas son mostradas tal como son. La obra se funde con la realidad, es real. Los materiales, débiles y de fuerte carácter perecedero (y dispuestos en contra de la gravedad por la posición vertical en que Spoerri los coloca) luchan por la supervivencia en un contexto y en una eternidad contra natura.

Esta segunda parte estudia las manifestaciones artísticas contemporáneas donde existe el empleo de alimentos como materia principal. Inspirándose en la tradición, estos creadores llegan mucho más lejos incorporando directamente la comida en sus piezas. Se muestran las obras que son referencia clave para la investigación, diferenciando de forma clara cuales son verdaderas obras de Eat Art y cuales poseen referencias directas a alimentos pero no existe presencia alguna de los mismos y, por tanto, se encuentran fuera del objetivo del presente estudio.

Se pudo formular por tanto en este apartado una diferencia clara: por un lado podemos encontrar artistas que trasladan la cocina o el restaurante a las salas de exposiciones, donde cobran una nueva dimensión, espacios que se trasforman y no sólo esperan ser vistos y recorridos, también ser olidos y comidos. En ellos se deja que el espectador toque y llegue a comerse las obras que aparentemente sólo están para ser miradas. Otros artistas crean verdaderos restaurantes sirviendo menús determinados a los asistentes, jugando con las formas, los colores o los títulos de los platos mostrados, creando un ambiente y un discurso que ayuda a la comprensión e introducen en la performance, en el universo único del confabulador del espectáculo. La comida se comporta como el medio por el cual la idea o el mensaje del artista llega al público [figura 3].

Otras creaciones no permiten la destrucción de la obra por parte del observador; ésta funciona como una verdadera escultura, un volumen tridimensional que puede recorrerse espacialmente y con la mirada, la comida presente le da significado pero no está para comerse. Dentro de estas piezas realizadas con comida para ser mirada, algunos artistas llegan más lejos indagando en su carácter efímero, mostrando a los espectadores estados avanzados de descomposición y lo que éstos pueden causar en otros materiales o en nuestra propia percepción. Existen además obras que aun mostrando comida, lo hacen de forma poco directa, ya sea mediante vídeos o fotografías, aquí la obra precisa de materiales orgánicos como los alimentos para dar sentido a su discurso, pero el material fue usado por el artista en solitario y es mostrado posteriormente en forma de documento. La obra ha perdido por tanto la parte orgánica, su resultado es un material alejado de la comida, su soporte es diferente a los anteriores, pero pertenece al catálogo general del Eat Art. 
Este estudio desembocó en el diseño de una tabla que agrupa las distintas tipologías, con las que poder seguir avanzando en el proyecto de forma clara y concisa: [tabla 1]

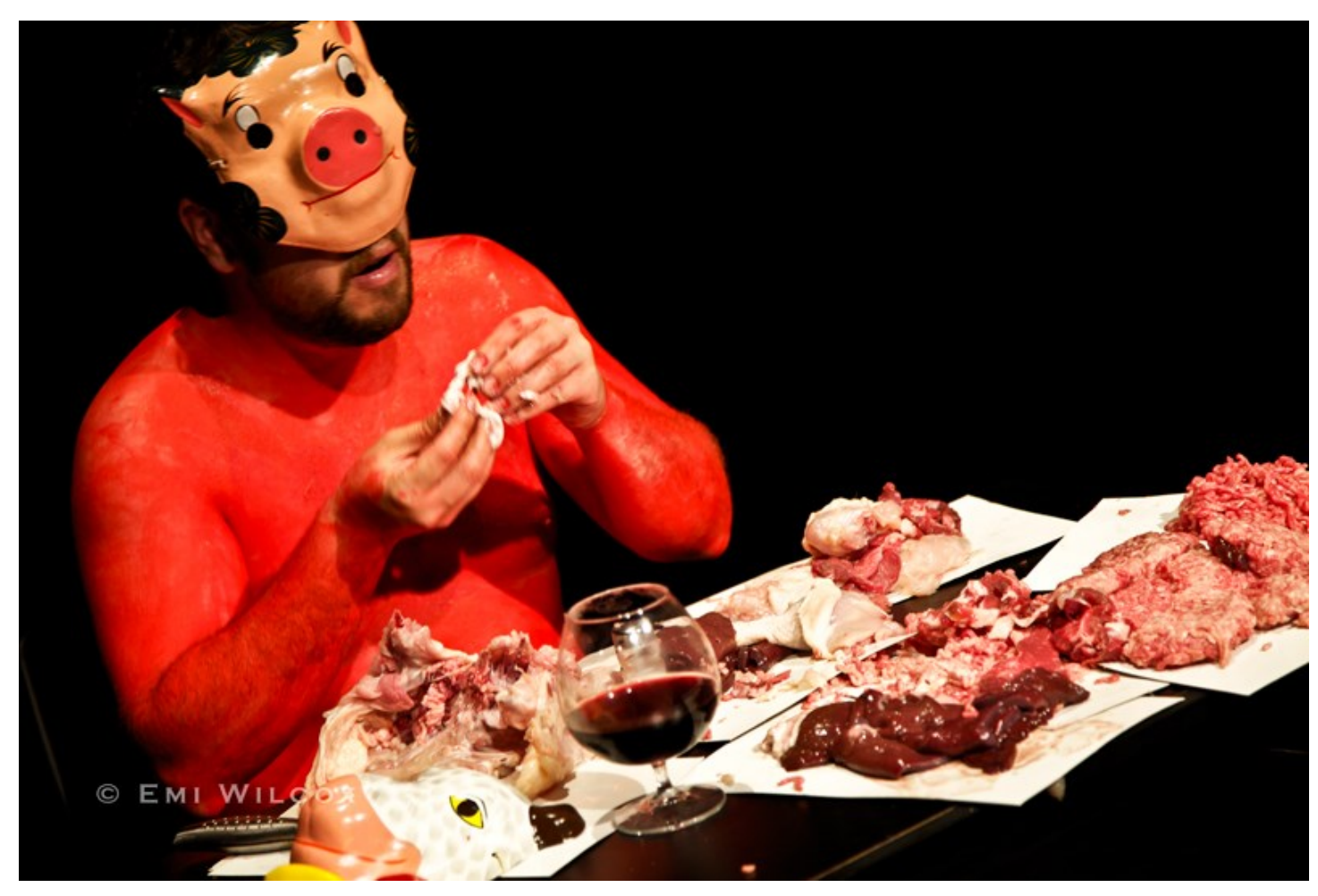

Figura 3. Banquete Atropoozoomórfico, Emi Wilcox. Performance. CJL Pérez Buitrago.

Tabla 1 de Tipologías de obras Eat Art/estrategias para su conservación y restauración.

\begin{tabular}{|c|c|c|c|c|}
\hline \multicolumn{3}{|c|}{ Obras CON presencia física de comida } & \multicolumn{2}{|c|}{ Obras SIN presencia física de comida } \\
\hline $\begin{array}{l}\text { Obras de carácter } \\
\text { duradero }\end{array}$ & $\begin{array}{l}\text { Obras de carácter } \\
\text { perecedero }\end{array}$ & $\begin{array}{l}\text { Obras que implican } \\
\text { una acción artística }\end{array}$ & Fotografía & Video arte \\
\hline $\begin{array}{l}\text { La obra está ideada } \\
\text { para que sus } \\
\text { materiales no } \\
\text { perezcan y se } \\
\text { conserven en el } \\
\text { estado en que } \\
\text { originalmente fueron } \\
\text { dispuestos por el } \\
\text { artista. }\end{array}$ & $\begin{array}{l}\text { La obra está ideada } \\
\text { para que sus } \\
\text { materiales } \\
\text { permanezcan } \\
\text { inmutables. La } \\
\text { intención del artista } \\
\text { radica en mostrar el } \\
\text { proceso de deterioro } \\
\text { natural y el resultado } \\
\text { de la degradación } \\
\text { producida. }\end{array}$ & $\begin{array}{l}\text { La obra está ideada } \\
\text { para que el } \\
\text { espectador } \\
\text { interáctue con la } \\
\text { misma de una forma } \\
\text { concreta, } \\
\text { previamente, ideada } \\
\text { por el artista, en } \\
\text { muchas ocasiones } \\
\text { acompañado de } \\
\text { actos o rituales } \\
\text { marcados. }\end{array}$ & $\begin{array}{l}\text { La obra fotográfica } \\
\text { presenta imágenes } \\
\text { que para su discurso } \\
\text { artístico precisan de } \\
\text { la aparición de } \\
\text { comida, ya sea en } \\
\text { condiciones } \\
\text { naturales o } \\
\text { manipulada } \\
\text { previamente }\end{array}$ & $\begin{array}{l}\text { La obra de video arte } \\
\text { presenta imágenes } \\
\text { que para su discurso } \\
\text { artístico precisan de } \\
\text { la aparición de } \\
\text { comida, ya sea en } \\
\text { condiciones } \\
\text { naturales o } \\
\text { manipulada } \\
\text { previamente. }\end{array}$ \\
\hline
\end{tabular}




\section{Parte III. Problemática específica del Eat Art}

Estudiado lo que significa una obra de Eat Art, habiendo dejado claras las claves para su comprensión, lectura y los tipos de obras que pueden encontrarse, se realizó un esquema conciso donde quedaban expuestas en forma de grupos diferenciados. Teniendo conocimiento de las clases y su carácter específico se analizaron las problemáticas derivadas de cada grupo, dependiendo de si el deterioro es realmente un daño directo hacia la obra o se trata de un proceso degenerativo buscado por el artista, se evaluaron las posibles causas y los inconvenientes de su presencia en la obra. De igual forma se planteó la cuestión de la idea o concepto frente a la materia constituyente. Esta fase se centró en las piezas en las que existía presencia física de comida, dejando los soportes celulósicos y el video arte fuera del estudio.

Obras con carácter duradero, perecedero o de carácter participativo no suponen, en ningún caso, el mismo conflicto para el conservador-restaurador. En el caso de obras con intención de durabilidad en el tiempo se presenta una problemática derivada de su constitución, en segundo lugar de su incomprensión o falta de información y en tercer lugar a causa de sus condiciones expositivas. En piezas que implican una acción artística (performance art) el problema puede proceder por un lado de su propia naturaleza y por otro, al igual que en el anterior caso, por incomprensión o falta de información. Por último, en obras de carácter perecedero sus problemas derivarán de su degradación -en cuanto que afecten al resto de la colección o piezas expuestas cerca-, de sus condiciones expositivas y su incomprensión algo común en los tres tipos que puede causar la tergiversación del discurso y de sus formas. Tras analizar las patologías frecuentes de numerosas obras se concluyó que cada tipo coincidía en una serie de funciones o finalidades más o menos similares, por lo que la tabla iniciada en el segundo capítulo se completó con estas especificidades que provocan unas problemáticas u otras en la pieza, lo que determinará la estrategia a diseñar para su preservación.

\section{Parte IV. Estrategias en conservación-restauración de obras Eat Art}

Finalmente el estudio se enfocó en desarrollar estrategias específicas para el tratamiento de obras de Eat Art, refiriéndose en todo momento al sistema de división formulado anteriormente. Se establecen tratamientos o formulas singulares para cada tipología, dejando claras las pautas a seguir y la actitud que debería tomarse a la hora de enfrentarnos a una pieza con unas determinadas características.

La presente investigación indaga en cuestiones referidas a la materia, la parte física de la obra: la comida. En el arte contemporáneo, lo material es sólo una de las muchas caras que nos presenta el artista. El contenido así como el significado y su mensaje son valores que en la mayoría de la ocasiones cobran más relevancia que el propio cuerpo de la pieza. Al estudiar una obra concreta, puede verse cómo no existe una marcada separación entre concepto y materia. Ambas propiedades van parejas, son inseparables. Si un especialista subsana el daño en una tableta de chocolate, sustituye una barra de pan o hace una réplica de un caramelo, inevitablemente tanto la parte física como la conceptual estarán siendo modificadas, ya sea permitiendo la sustitución y variación de los materiales o por el contrario respetando su inalterabilidad y mantenimiento de los originales. Ahora bien, esto podrá ser una acción permitida por el artista y encajar perfectamente con la intención de la pieza, pero en otros casos puede que se trate de una acción injustificable que trastoque la esencia de la obra. Por ello debe tenerse mucha precaución con la estrategia o el tratamiento seleccionado, concediéndosele la importancia justa a cada parte. Se evitará de este modo, caer en errores a la hora de conservar partes u objetos superfluos, otorgándoles más 
importancia de la que verdaderamente reclaman. Este estudio pretende facilitar esa labor, mostrando estrategias a emplear desde la intención del propio autor. Un ejemplo sería la conservación del material, o materia constituyente, procurando su perdurabilidad ante el paso del tiempo. Pero también podremos enfrentarnos a la conservación de la idea o intención original, permitiendo que la obra se deteriore y termine destruyéndose, no atendiendo por ende a su parte física.

Cada una de las distintas acciones que podrán llevarse a cabo estarán determinadas por el carácter específico de la obra. Debido a todo ello, existen situaciones donde la decisión a tomar puede presentar un conflicto debido a intereses secundarios: ya sea por parte de una institución, el propio artista, el museo o el dueño. El trabajo del conservador se centrará por tanto, en dar las soluciones más adecuadas para mantener la intencionalidad artística, nunca el interés de un tercero. Si se trata de una obra efímera, dicha pieza deberá perecer, de igual modo una obra con una posición concreta en el espacio o que necesita de una interacción del público no deberá modificarse. Si esto sucediera estaríamos ante una mala opción de conservación, desvirtuando el concepto que el autor imprimió en la misma.

Al adoptar un criterio para el tratamiento de una obra, éste deberá responder entre otras problemáticas a sus cuestiones legales. Es necesario tener total conocimiento de la situación de la pieza, respetar los derechos morales del autor, y saber por un lado si el mismo está vivo, y por otro, quién es su dueño actual. Existe una normativa que debería responder a las problemáticas que se plantean durante el tratamiento del arte más actual, pero lamentablemente encontramos líneas que deberían revisarse ya que son confusas y contradictorias con gran parte del catálogo contemporáneo. Son necesarias nuevas definiciones legales que ayuden en la aplicación de la normativa sobre obras de difícil interpretación, así como un estudio de los derechos que se adquieren con una obra y los que sigue manteniendo el creador. Ambas revisiones evitarían posibles enfrentamientos surgidos durante la restauración-conservación. Una mejora en la Ley de Propiedad Intelectual flexibilizaría la adaptación y correcto empleo de la misma. Creaciones artísticas como las revisadas, que poseen un carácter finito y deben destruirse con el tiempo o por la interacción del espectador, no siempre están bien contempladas en las normativas vigentes, las cuales instan a la conservación de la obra física por encima de otros factores.

Con todas estas consideraciones, el resultado primordial del estudio se centra en instaurar y poner a disposición del lector una metodología precisa para facilitar la comprensión del Eat Art y permitir el abordaje desde el punto de vista de la conservación. Para ello, se ha tenido en cuenta algo que desempeña un papel destacado en todo proceso de restauración: el poseer un conocimiento preciso para conseguir aplicar un procedimiento acertado que ayude a la preservación de la pieza y no entorpezca la correcta lectura de la misma. Se evitará con ello la pérdida total de ésta o su mala interpretación, lo que daría como resultado en cualquier caso, su mutilación [tabla 2].

Analicemos a modo de ejemplo alguna obra de Eat Art, para de este modo aplicar el recorrido indicado en la tabla hasta dar con una posible estrategia a seguir. Observemos una obra de Thomas Rentmeister, artista que ha trabajado en numerosas ocasiones con alimentos para dar salida a su interior reflexivo de una forma tridimensional sencilla y efectiva. En una de sus obras, Rentmeister altera notablemente los significados de un retrete común y una simple crema de chocolate para untar, el resultado es Mr. Clever. En la sala podremos observar un urinario lleno hasta arriba de la crema con un oscuro aspecto. Poniendo en evidencia la fuerza visual de la Nutella sacada de su contexto habitual, la alteración es evidente e invita a la reflexión de los significados prefijados que nos rodean. 
Tabla 2 de Tipologías de obras Eat Art/estrategias para su conservación y restauración.

TIPOLOGÍAS DE OBRAS DE EAT ART / ESTRATEGIAS PARA SU CONSERVACIÓN Y RESTAURACIÓN

\begin{tabular}{|c|c|c|c|}
\hline & Carácter & Función y finalidad & $\begin{array}{l}\text { Estrategias de conservación } \\
\text { restauración }\end{array}$ \\
\hline \multirow[t]{2}{*}{$\begin{array}{l}\text { Obras de } \\
\text { carácter } \\
\text { duradero }\end{array}$} & \multirow{2}{*}{$\begin{array}{l}\text { La obra está ideada para } \\
\text { que sus materiales no } \\
\text { perezcan y se conserven } \\
\text { en el estado en que } \\
\text { originalmente fueron } \\
\text { dispuestos por el artista. }\end{array}$} & $\begin{array}{l}\text {-Función estética o visual. } \\
\text {-Función operativa. }\end{array}$ & -Reposición \\
\hline & & -Función estética o visual. & $\begin{array}{l}\text {-Reposición } \\
\text {-Sustitución } \\
\text {-Recreación }\end{array}$ \\
\hline \multirow[t]{2}{*}{$\begin{array}{l}\text { Obras de } \\
\text { carácter } \\
\text { perecedero }\end{array}$} & \multirow{2}{*}{$\begin{array}{l}\text { La obra está ideada para } \\
\text { que sus materiales } \\
\text { permanezcan } \\
\text { inmutables. La intención } \\
\text { del artista radica en } \\
\text { mostrar el proceso de } \\
\text { deterioro natural y el } \\
\text { resultado de la } \\
\text { degradación producida. }\end{array}$} & $\begin{array}{l}\text {-Descomposición tras la } \\
\text { degradación máxima -pérdida } \\
\text { de la pieza- }\end{array}$ & -Reactivación \\
\hline & & $\begin{array}{l}\text {-Mantenimiento del desecho } \\
\text { como resultado final. }\end{array}$ & $\begin{array}{l}\text {-Plastinación } \\
\text {-Momificación } \\
\text {-Disecación }\end{array}$ \\
\hline \multirow{2}{*}{$\begin{array}{l}\text { Obras que } \\
\text { implican una } \\
\text { acción } \\
\text { artística } \\
\text { performance }\end{array}$} & \multirow{2}{*}{$\begin{array}{l}\text { La obra está ideada para } \\
\text { que el espectador } \\
\text { interáctue con la misma } \\
\text { de una forma concreta, } \\
\text { previamente, ideada por } \\
\text { el artista, en muchas } \\
\text { ocasiones acompañado } \\
\text { de actos o rituales } \\
\text { marcados. }\end{array}$} & $\begin{array}{l}\text {-Acción en que el artista es el } \\
\text { único que entra en contacto } \\
\text { con la comida. Mientras es } \\
\text { observado por el espectador. }\end{array}$ & -Recreación \\
\hline & & $\begin{array}{l}\text {-Acción en que el público entra } \\
\text { en contacto con la comida. }\end{array}$ & -Reactivación \\
\hline
\end{tabular}

El problema más evidente que surge al rato de analizar la pieza no radica en la conservación del sanitario, el cual presenta una fácil preservación y las alteraciones que se le pueden plantear son pocas y los tratamientos no variarán mucho de la retirada de polvo y protección, buen almacenamiento y correcto embalaje para transporte. Fijando la atención ahora en el contenido, la crema de cacao, sí surgen interrogantes. En primer lugar el artista está vivo y previsiblemente no resultará difícil ponerse en contacto con él, o hacerlo la institución interesada en adquirir la pieza en cuestión. Las medidas que deberán tomarse con ella podrán ser analizadas junto a su creador, pero ya que se trata de una hipotética estrategia, debatamos diferentes opciones.

En primer lugar surge el interrogante del mantenimiento de la obra en sala, tareas normales de limpieza de depósitos superficiales o revisar que todo esté en correcto estado se vuelven mucho más complicados al tratarse de una superficie «pegajosa» altamente atrayente para gran cantidad de partículas de suciedad. Dadas las características de la Nutella, toda mota de polvo o partícula sólida será muy probable que termine incrustada en la crema dulce, al igual que cualquier acto «vandálico» o accidental que pueda provocar el visitante, como tirar cualquier papel o pequeño 
objeto dentro del chocolate o incluso tocar el alimento. Estas alteraciones, que en cualquier obra se solucionarían pasando un paño de microfibra, un plumero o aspirando, en $\mathrm{Mr}$. Clever se vuelven prácticamente irrealizables. Se puede sumar a todo esto, el hecho de tratarse de comida, foco de ataque para cualquier insecto o roedor, sin olvidar la biodegradación del material y la probable aparición de moho.

Se han dado casos similares en museos y centros, donde las actuaciones han estado muy marcadas por la reposición y la sustitución. Ambas medidas son entendibles en el momento en que se habla de materiales que no están conformados por la mano artesanal del artista y pueden provocar conflictos como los planteados. Por todo ello se opta por soluciones que no provoquen falseamientos muy evidentes ni cambios en la obra. Un buen ejemplo de este tipo de actuaciones es la solución que se dio en la obra Energía de Wolf Vostell, expuesta en el Museo Vostel Malpartida. En esta pieza se realizó la sustitución de una serie de barras de pan que se encuentran envueltas en periódicos y apiladas junto a un coche. Se trata de una obra expuesta de forma permanente en el museo, y como medida de conservación se decidió la sustitución de todas las barras por réplicas realizadas en escayola pintada. La apariencia final respeta al máximo la estética de la pieza, y si no se llega a tocar o se pregunta, el pan parece verdaderamente pan. Se trata de una solución entendible, además de por el gran número de barras, por el fácil mantenimiento de los facsímiles. Estos no serán atacados por insectos -hecho importante tratándose de un museo en medio de la naturaleza- y podrán limpiarse cómodamente con los utensilios adecuados para ello.

Con la sustitución analizada se expone una posible solución, la creación de una réplica con otros materiales que produzcan una forma física que sea igual al original, tanto en color, textura y densidad. Otras obras podrían abordarse desde la sustitución constante de un elemento cuando éste presente algún problema. Así sucede en las piezas de Victor Grippo, en las que la vida del material, en su caso patatas, es fundamental para la resolución de la pieza, ya que la energía que generan los tubérculos es capaz de hacer funcionar distintos elementos electrónicos. Algunas de sus obras se muestran así de sencillas: unas pocas patatas o un gran número de ellas, se conectan a diversos aparatos que funcionan gracias a las mismas. Este hecho obliga irremediablemente al poseedor de la obra a sustituir las patatas que ya estén degradadas y no propulsen el funcionamiento de los elementos seleccionados por Grippo. Realizar una réplica o facsímil en este caso no surtiría efecto y el resultado sólo sería estético pero la pieza no se vería completada. Un caso similar sucede en la conocida obra de Felix Torres Untitled (portraid of Dad) de 1991, en que el artista dispone en una esquina de la sala de exposiciones una montaña de caramelos en cuya cartela se especifica el peso del conjunto: $79,4 \mathrm{Kg}$. El espectador puede tomar del conjunto uno de los dulces, la montaña entonces irá disminuyendo hasta desaparecer. Torres nos hace participes de su amor y su dolor haciendo que contribuyamos en el adelgazamiento de su pareja, viendo cómo se pierde, «adelgaza» y muere.

Cuando nos situamos frente a piezas que presentan una intención interactiva con el público, las medidas a tomar se vuelven complejas y los modos de exposición delicados. Una obra como Chair Event del artista George Brecht, tiene una dinámica interactiva muy marcada pero en muchas ocasiones al ver este tipo de piezas expuestas asistimos a modos expositivos que presentan objetos totalmente inertes, vacíos de toda acción, expuestos sólo para ser mirados. Brecht indaga con sus obras en el mundo de las galerías y los museos, en la forma que en ellas se exponen las piezas, pasando del objeto sacralizado e inmaculado a una obra útil con posibilidad de cambio. Sus sillas se presentan para ser usadas, movidas y variadas, así como los otros enseres que pueden localizarse sobre estas sillas: naranjas, pedazos de pan... Su intención es la participación por parte del público con todo ello, nunca el mostrar las sillas en vitrinas o tarimas que alejan el discurso real 
del contacto con el espectador. Este tipo de obras que presentan una acción necesaria, siempre deben guardar para el futuro los mecanismos óptimos para que sigan funcionando. Las estrategias a diseñar deben pues permitir que la obra siga viva, ya sea reactivando estas acciones y dejando con ello que los objetos sigan degradándose por el usuario o recreándolas por medio, por ejemplo, de replicas de los mismos. Los materiales y objetos que Brecht muestra en sala no pretenden luchar contra el paso del tiempo, por lo que podrían ser sustituidos sin problemas.

\section{Conclusiones}

En el Eat Art, como se ha visto a lo largo del estudio, los alimentos ya no se limitan a ser representados, éstos mismos dan cuerpo a esculturas y espacios por entero comestibles. En ellos, el espectador interacciona no sólo con la vista, también con el olfato, las manos y la boca. Los hermanos Grimm nos presentaban en su cuento a la malvada bruja que intentaba devorar a los pequeños Hansel y Gretel. Con sus dulces creaciones, casas de jengibre, pastel y azúcar, mobiliarios de chocolate y un sinfín de apetecibles invenciones, se concebían obras fantásticas en las que perderse, investigar y deleitarse. La malvada bruja no es otra que Sonja Alhäuser y César Martínez y Dorothée Selz y Leandro Erlich... artistas que se encargan de conformar espacios donde imaginar y repensar la vida [figura 4].

Al igual que los niños perdidos del cuento, estos artistas hacen que el espectador caiga en la trampa, forme parte de su mundo y le ayude a formular sus idearios dando con su participación significado a la obra. Y aunque la transcripción más exacta del Eat Art sea "arte comida», "arte comestible» o "come arte», muchas de las piezas no son necesariamente degustables, y sus creadores intentan mostrar otros aspectos que acompañan a la comida, tales como su frescor, su olor o el paso del tiempo sobre materias altamente degradables. El trabajo de Manzoni, Jana Sterbak, Dieter Roth o Victor Grippo, coinciden en emplear comida real pero ninguno lo hace con la misma intención. Cada creación guarda componentes diversos y responden en el tiempo y al lugar de forma diferente. Mientras que Manzoni o Grippo pretenden presentar los alimentos siempre frescos, vivos y con aspecto saludable, Dieter Roth o Antony Gormley se interesan en exhibir lo putrefacto y revelar la destrucción de lo vivo. Posiblemente sería más acertado en todos estos casos hablar de Food Art «arte con alimentos», pero aún así el término Eat Art hace referencia al empleo de comida real para conformar la pieza de arte y así es como se ha entendido en el presente proyecto, para con él dar soluciones en la formación de estrategias de conservación de estas complejas piezas.

Existen como se ha expuesto, diferencias generales y específicas entre unos tipos de obras Eat Art y otras. Esta disparidad ha dado como resultado una tabla [tabla 2], resultado final y conclusión del estudio. Como respuesta a todas las problemáticas expuestas se diseñaron soluciones que podrían darse a cualquiera de los tipos de obras y a sus diferentes conflictos. Se barajaron actuaciones muy diversas con las que el restaurador puede hacer perdurar, reactivar o incluso re-interpretar las obras, siendo en todos los casos opciones e ideas que han sido trazadas de forma teórica, funcionando como guía para actuar de una manera u otra respecto a su función y finalidad. 


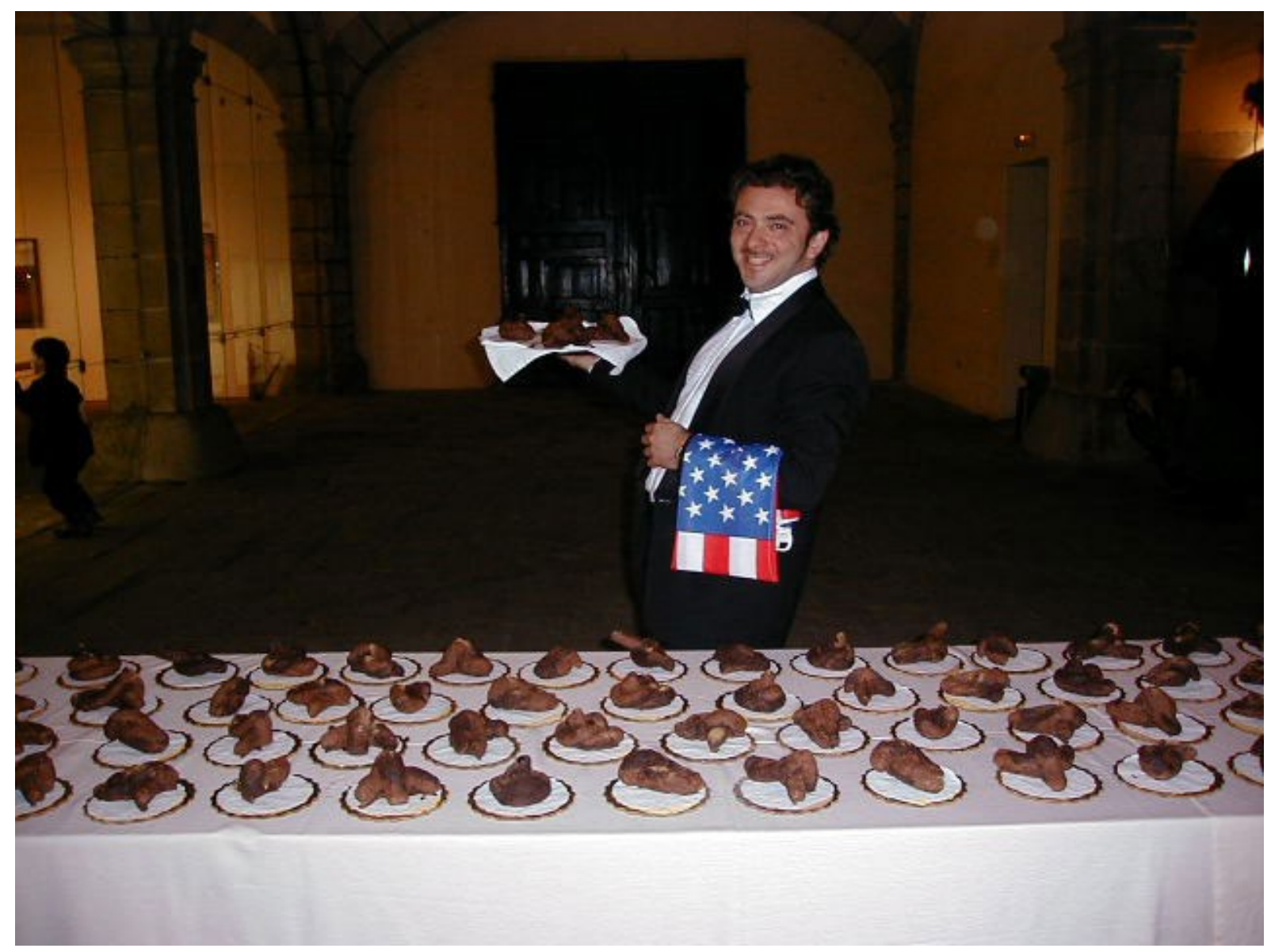

Figura 4. Como luego existo, existo luego como, César Martínez. Esculturas con forma de excremento realizadas con chocolARTE, mazapanes, turrón y esencia de tequila que el público de la exposición degustó y saboreó durante la inauguración. 2002. @Antoni Abad.

Cabe señalar que con la variedad de materiales y procederes vistos, sería impracticable tratar de realizar un panorama detallado al milímetro de las distintas soluciones que la conservación y restauración pueden dar. Por eso la intención se centra en realizar un esquema claro y conciso donde queden reflejados todos los tipos de obras Eat Art que puedan existir, reduciéndose estos a tres tipologías: Obras de carácter duradero, Obras de carácter perecedero y Obras que implica una acción artística. Tras ello se indica cual puede ser su función y finalidad respecto a ese carácter, ya sea funcional y visual, solamente estético o de interacción, e incluso degradación máxima. De este modo, obras como Mr. Clever, con presencia real de comida, presenta una intención únicamente visual y sumado a ello no posee ningún interés en mostrar la degradación de la crema ni por tanto su desaparición. Siguiendo el recorrido en la tabla, las posibles estrategias a aplicar serían la reposición o sustitución y la recreación. Al igual sucede con la obra Energía de Vostell, pero a diferencia de éstas, las patatas de Grippo instan a una estrategia muy clara, la sustitución. Cualquier otra opción no permitiría el funcionamiento de la obra. De modo similar ocurriría al desarrollar una réplica en otro material de los caramelos de Félix Torres, lo que imposibilitaría que el público participase en la disminución y desaparición de su montaña de dulces.

A modo de colofón y nexo entre la introducción del artículo, cabe retomar la cita con que se inició la explicación del estudio abordado, perteneciente al fabuloso recetario de Marinetti, La Cocina 
Futurista: Una comida que evitó un suicidio. En ella quedaban esbozados los acontecimientos que se sucedieron en casa de uno de los compañeros del artista, Giulio Onesti, y los motivos que les llevaron a crear un muestrario de mujeres comestibles. Con el transcurso de la historia se van desgranando más datos sobre la obra en cuestión, pero sería interesante resaltar otro magnifico momento, en que una mujer real irrumpe en la sala donde aguardan los amigos junto a la obra comestible ya acabada: No me toméis por necia -murmuró con gracia lánguida estoy atontada. Vuestro ingenio me espanta. Os suplico que me Expliquéis las razones, las intenciones, los pensamientos que os han dominado mientras esculpíais tantos delicioso olores, sabores, colores y formas (Marinetti 1985:19).

Extrañada por lo observado en la sala, la mujer sorprendida no entiende lo que ve e instintivamente pide explicaciones a sus creadores. Dejando aparte la sugestiva respuesta con que Marinetti deslumbra a la confundida mujer, tomemos la historieta y todo lo acontecido como metáfora, como un símbolo o alegoría de la situación del restaurador-conservador frente a la obra contemporánea hecha con comida. Este conflicto es el detonante que dio pie a la realización del estudio que aquí presento de forma escueta. Mi intención es esclarecer los interrogantes que presenta, en mayor medida si cabe, para los encargados de preservar dichas creaciones. Somos responsables, en todos los aspectos, de su estado para con el futuro y de que el público que acuda a deleitarse con estas creaciones, denominemos atípicas, sigan disfrutando correctamente de una pequeña parte del vasto catálogo artístico de nuestros días.

\section{BIBLIOGRAFÍA}

AZNAR ALMAZÁN, S. (2000). El arte de acción. San Sebastián: Editorial Nerea.

BAIGORRI BALLARÍN, L. (1997). El video y las vanguardias históricas. Barcelona: Ed. Universitat de Barcelona.

BRILLANT-SAVARIN, J.A. (2001). Fisiología del gusto. Barcelona: Editorial Optima.

BERMEJO BARRERA, J.C. GONZÁLEZ GARCÍA, F. J. y REBOREDO, S. (1996). Los orígenes de la mitología griega. Madrid: Ediciones Akal.

BROWNING, W.R.F. (2006). Diccionario de la Biblia: Guía básica sobre los temas, personajes y lugares bíblicos. Barcelona: Ediciones Folio.

BUSTINDUY, P. (2005). "La presencia de alimentos en obras de arte. Problemas para su conservación", en VI Reunión del Grupo de Arte Contemporáneo del GEIIC. Madrid: Grupo Español del IIC, Museo Nacional Centro de Arte Reina Sofía, 95-100.

CHARLESP, V. (2011). Naturaleza Muerta. Londres: Parkstone International.

ESPÍN CÁNOVAS, D. (1997). Los derechos de autor de obras de arte. Madrid: Cívitas.

BERCOVITZ, G. (1997). Obra plástica y derechos patrimoniales de su autor, Madrid: Tecnos.

GOUGH, R. (1999). On Cooking: Performance Research, UK: Routledge.

HEUMAN, J. (1995). From marble to chocolate: the conservation of modern sculpture. Londres: Tate Gallery Conference, 18-20 September.

OGDEN, J. (2005). Psicología de la alimentación. Madrid: Morata.

KORSMEYER, C. (2002). El sentido del gusto: comida, estética y filosofía. Barcelona: Paidos Transiciones.

GOMBRICH, E.H. (2006). La Historia del Arte. Madrid: Debate.

SERRERA CONTRERA, J.M. Y VALDIVIESO, E. (1985). Historia de la Pintura Española: Escuela Sevillana del Primer Tercio del Siglo XVII. Madrid: Instituto Diego Velázquez: Consejo Superior de Investigacione Científicas. 
MARINETTI, F. T. (1985). La cocina futurista: una comida que evitó un suicidio. Barcelona: Gedisa.

MUÑOZ VIÑAS, S. (2003). Teoría Contemporánea de la restauración. Madrid: Editorial Síntesis.

PASCUAL ANDERSON, M. DEL R., CALDERÓN Y PASCUAL, V. (2000). Microbiología Alimentaria: Metodología Analítica para Alimentos y Bebidas. Madrid: Editorial Diaz de Santos.

RIGHI, L. (2006). Conservar el Arte Contemporáneo, San Sebastián: Editorial Nerea.

ROTAECHE, M. (2010). Conservación y restauración de materiales contemporáneos y nueva tecnologías. Madrid: SINTESIS.

ROUTH, J. Y ROUTH, S. (2009). Notas de cocina de Leonardo Da Vinci. Madrid: Temas de Hoy.

STANGOS, N. (2000). Conceptos del arte moderno. Barcelona: Ediciones Destino.

TATARKIEWICZ, W. (2004). Historia de la estética III: La estética moderna 1400-1700. Madrid: Akal.

VV.AA. (2002). Comer o no Comer. Salamanca: Ed. Centro de Arte de Salamanca (CASA).

VV.AA. (2011). Conservación de Arte Contemporáneo 8a Jornada. Madrid: MNCARS Versiones del sur.

VV.AA. (2011). Conservación de Arte Contemporáneo 11 a Jornada. Madrid: MNCARS Versiones del sur.

VV.AA. (2011). Conservación de Arte Contemporáneo 12a Jornada. Madrid: MNCARS Versiones del sur.

VV.AA. (1996). ¿Deshumanización del arte?, Salamanca: Universidad Salamanca.

VV.AA. (2009). Eating the Universe: Vom Essen in der Kunst, Kunsthalle Düsseldorf: Editorial DuMont.

VV.AA. (2009). Martha Rosler: la casa, la calle, la cocina. Madrid: Centro José Guerrero.

VV.AA. (2010). Miralda de gustibus non disputandum. Madrid: La Fábrica Editorial.

VV.AA. (2010). No es sólo lo que ves: pervirtiendo el minimalismo. Madrid: MNCARS Versiones del sur.

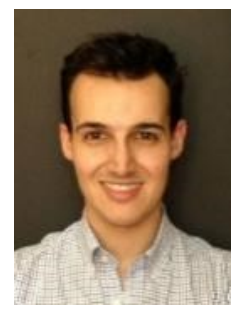

Lorenzo Hortal Valverde

hortalv@gmail.com

Lorenzo Hortal Valverde, licenciado en Bellas Artes por la Universidad Complutense de Madrid con especialidad en Restauración y Conservación de pintura. Magíster en Restauración y Conservación de Arte Contemporáneo (UCM y MNCARS). Ha realizado prácticas en el departameno de restauración del Museo Nacional Centro de Arte Reina Sofía. Actualmente y desde 2011 trabaja en el estudio Icono I\&R S.C. en la restauración y estudio de pintura de caballete mediante el tratamiento directo de las obras y su estudio analítico en laboratorio. Compaginándo esta labor con su colaboración en Nicolas Lemmens Studio, Bruselas, tratando exclusivamente obra contemporánea.

Artículo enviado el $31 / 01 / 2013$

Artículo aceptado el 28/05/2013 